\title{
Understanding the role of feed manufacturing and delivery within a series of porcine deltacoronavirus investigations
}

\author{
C. Grace Elijah, DVM; Olivia L. Harrison; Allison K. Blomme; Jason C. Woodworth, PhD; Cassandra K. Jones, PhD; \\ Chad B. Paulk, PhD; Jordan T. Gebhardt, DVM, PhD
}

\section{Summary}

Two feed mills and three breed-to-wean facilities were investigated after being diagnosed with porcine deltacoronavirus (PDCoV) with initial suspicion that feed manufacture and delivery processes were involved in disease transmission. Both feed mills were audited, and environmental samples collected in areas that were deemed high risk for virus contamination. All breed-to-wean facilities had PDCoV detected as would be expected, while the only positive samples for enteric coronaviruses associated with feed mills were feed delivery trucks. These results indicate that feed delivery surfaces can help spread virus during an ongoing disease outbreak and must be considered when determining the outbreak origin.

Keywords: swine, epidemiology, feed safety, porcine deltacoronavirus

Received: January 20, 2021

Accepted: April 21, 2021

\section{Resumen - Comprensión del rol de la fabricación y entrega de alimento bal- anceado durante una serie de investiga- ciones sobre deltacoronavirus porcino}

Se investigaron dos fábricas de alimento y tres instalaciones de gestación a destete después de ser diagnosticadas con deltacoronavirus porcino (PDCoV) y con la sospecha inicial de que los procesos de fabricación y entrega de alimento estaban implicados en la transmisión de la enfermedad. Ambas fábricas de alimento fueron auditadas y se recolectaron muestras ambientales en las áreas consideradas de alto riesgo de contaminación del virus. Todas las instalaciones, como era de esperar, desde la gestación hasta el destete fueron positivas al PDCoV, mientras que las únicas muestras positivas a coronavirus entérico asociados con las fábricas de alimento fueron los camiones de reparto de alimento. Estos resultados indican que las superficies de distribución de alimento pueden ayudar a propagar el virus durante un brote activo de la enfermedad y deben tomarse en cuenta al determinar el origen del brote.

\begin{abstract}
Résumé - Comprendre le rôle de la fabrication et de la livraison d'aliments pour animaux dans une série d'enquêtes sur le deltacoronavirus porcin
\end{abstract}

Deux usines d'aliments pour animaux et trois installations de type accouplementsevrage ont fait l'objet d'une enquête après avoir reçu un diagnostic de deltacoronavirus porcin (PDCoV) avec la suspicion initiale que les processus de fabrication et de livraison des aliments étaient impliqués dans la transmission de la maladie. Les deux meuneries ont été auditées et des échantillons environnementaux ont été prélevés dans des zones jugées à haut risque de contamination virale. Comme on pouvait s'y attendre, le PDCoV fut détecté dans toutes les installations de type accouplement-sevrage, tandis que les seuls échantillons positifs pour les coronavirus entériques associés aux meuneries étaient des camions de livraison d'aliments. Ces résultats indiquent que les surfaces de distribution des aliments peuvent aider à propager le virus lors d'une épidémie en cours et doivent être prises en compte lors de la détermination de l'origine de l'épidémie.

Within the last decade, feed safety became heavily emphasized once it was hypothesized that a contaminated batch of feed ingredients imported from Asia was responsible for bringing PEDV and PDCoV to the United States. ${ }^{2}$ Prior to realizing that feed can serve as a vector for virus transmission, feed safety concerns primarily focused on controlling Salmonella, other bacteria, and mycotoxins in feed mills. Since then, scientists

CGE, JTG: Department of Diagnostic Medicine/Pathobiology, College of Veterinary Medicine, Kansas State University, Manhattan, Kansas.

OLH, JCW, CKJ: Department of Animal Sciences and Industry, College of Agriculture, Kansas State University, Manhattan, Kansas.

AKB, CBP: Department of Grain Science and Industry, College of Agriculture, Kansas State University, Manhattan, Kansas.

Corresponding author: Dr C. Grace Elijah, 1700 Denison Ave, Manhattan, KS 66506; Email: cgelijah@vet.k-state.edu.

This article is available online at http://www.aasv.org/shap.html.

Elijah CG, Harrison OL, Blomme AK, Woodworth JC, Jones CK, Paulk CB, Gebhardt JT. Understanding the role of feed manufacturing and delivery within a series of porcine deltacoronavirus investigations. J Swine Health Prod. 2022;30(1):17-23. 
have proven that PEDV-contaminated feed can cause clinical disease and once in the feed mill environment, impractical methods such as wet cleaning and disinfection are required to successfully remove PEDV from the feed mill. 3,4 Most feed safety research has focused on PEDV, but this research opened the door to the idea that a feed mill could serve as a transmission source of any virus. Currently, feed safety has a focus on bioexclusion of endemic pathogens as well as prevention of potential foreign animal disease introduction through feed and feed ingredients. The industry has also begun to further understand the epidemiological role the feed delivery supply chain has on feed mills and production sites. Taking what is known about fomites, such as people and trucks, feed safety research is working to understand the interaction between the feed mill and these moving pieces. Therefore, the authors conducted an investigation where multiple isolated facilities were diagnosed with PDCoV. The goals were to 1 ) understand if the feed mill was the origin of disease and 2) determine if trucks or people, either coming from the infected farms or coming from the feed mills, served as vectors to spread this virus.

\section{Case description}

\section{Herd histories}

Three swine breed-to-wean herds, designated as sites A, B, and C, were diagnosed with PDCoV within one week in November 2020, with reports of initial clinical signs in the gestation area of the respective facilities (Figure 1). All 3 sites were in the Midwest United States and operate in accordance with Pork Quality Assurance Plus guidelines. All diagnostic samples confirming clinical disease within the production sites were collected under standard veterinary oversight procedures. All environmental swabs were collected from surfaces with no animal contact and environmental sampling personnel did not enter the production facilities. Site A and B were operated by the same production system, whereas site $\mathrm{C}$ did not share any management oversight with the other two sites. Workers for site A reported clinical signs of PDCoV in the gestation barn on November 9, 2020, and the diagnosis of PDCoV was confirmed that afternoon via polymerase chain reaction (qPCR) from samples sent to Kansas State University Veterinary Diagnostic Laboratory (KSU VDL). Workers from site B reported clinical signs on November 9, 2020, and the diagnosis confirmed by Iowa State University Veterinary Diagnostic Laboratory (ISU VDL) on November 11, 2020.
Veterinarians from site B instructed workers to collect 1 feed sample from the gestation barn after confirmation of clinical signs of PDCoV. The sample was placed in the freezer and submitted to ISU VDL on November 30, 2020. Workers from site $C$ reported 60 animals with scours in the gestation barn on November 11, 2020. Site $C$ receives gilts from sites $\mathrm{A}$ and $\mathrm{B}$, but gilts are raised in offsite gilt development units (GDU) and the timeline of animal deliveries did not indicate an epidemiological link between site $\mathrm{C}$ and sites $\mathrm{A}$ and $\mathrm{B}$. A clinical diagnosis of PDCoV for site $\mathrm{C}$ was confirmed by laboratory evaluation the evening of November 11, 2020. Once PDCoV was diagnosed, all sites conducted controlled oral exposure with infected fecal material.

\section{Feed mill histories}

Feed mill 1 supplies site $C$ and 12 to 15 other sow farms and only makes swine diets. Prior to the outbreak on site $\mathrm{C}$, this feed mill monitored high risk areas such as boot soles, foot pedals, reclaim trucks, and office space every week. When clinical signs were first observed in gestation, the company reviewed their diets and determined that wheat middlings was the only ingredient unique to the gestation diet. Environmental samples were collected from all major ingredient bins, as it was believed that samples of accumulated dust would be

Figure 1: Timeline of events for feed mill investigation. Sites A, B, and C are three breed-to-wean facilities located in the Midwest. PDCoV = porcine deltacoronavirus; $q P C R=$ polymerase chain reaction; $K S U$ VDL = Kansas State University Veterinary Diagnostic Laboratory; ISU VDL = Iowa State University Veterinary Diagnostic Laboratory; PEDV = porcine epidemic diarrhea virus; TGEV = transmissible gastroenteritis virus.

\begin{tabular}{|c|c|}
\hline $11 / 9 / 2020$ & $\begin{array}{l}\text { Site A confirms PDCoV via qPCR at KSU VDL. } \\
\text { Site B collects a feed sample and stores it in the freezer. }\end{array}$ \\
\hline $11 / 11 / 2020$ & $\begin{array}{l}\text { Site B confirms PDCoV via qPCR at ISU VDL. } \\
\text { Site C displays clinical signs of PDCoV in the gestation barn. } \\
\text { Site C confirms PDCoV via qPCR. }\end{array}$ \\
\hline $11 / 12 / 2020$ & All sites conduct controlled oral exposure. \\
\hline $11 / 14 / 2020$ & KSU Feed Safety Team conducts feed mill investigation. \\
\hline $11 / 16 / 2020$ & 134 samples sent to ISU VDL for triplex qPCR for PEDV, PDCoV, and TGEV \\
\hline $11 / 18 / 2020$ & ISU VDL confirms 31 samples with detectable PEDV or PDCoV RNA \\
\hline $11 / 30 / 2020$ & Site B submits feed sample to ISU VDL for triplex qPCR for PEDV, PDCoV, and TGEV \\
\hline $12 / 2 / 2020$ & Site B feed sample is nondetectable for PEDV, PDCoV, or TGEV RNA \\
\hline
\end{tabular}


more representative over a longer period compared to subsamples of feed or feed ingredients. The mill investigated the transport and handling of the wheat middlings and determined that the trucks used for transportation were not used for any other purpose, such as transporting ingredients other than wheat coproducts.

Feed mill 2 supplied feed to sites A and B and supplied the same gestation feed to 3 other sites that also were infected with PDCoV but were not part of this investigation. Our investigation was focused on understanding the potential link between feed manufacture and delivery with acute outbreaks, so these additional three sites were excluded from this investigation because a significant amount of time had elapsed since clinical signs were noted at the farms. Feed delivery records reported that feed mill 2 delivered diets to site A and B from November 9-12, 2020, but what type of diet, how much, and what bin diets were delivered to are not recorded. Prior to this investigation, this feed mill had collected and submitted 7 environmental samples to the KSU VDL following initial clinical signs at a farm and suspicion of a potential link to the feed mill. All 7 samples were free of detectable PDCoV RNA and a link between the feed mill and farm outbreak was not found.

\section{Feed mill and production site investigations}

Investigations of the production sites and feed mill locations took place on November 14, 2020; approximately one week after observing clinical signs and confirming clinical diagnosis within production sites. Samples from sites A, $B$, and $C$ focused on feed contact and nonfeed contact surfaces outside of the barn. Environmental sampling was limited to feed bins of gestation, lactation, and GDU barns and areas of high foot traffic or potential for high viral load. No feed samples or environmental samples were collected interior to the entry shower because all sites conducted controlled oral exposure once confirming PDCoV on site, so environmental samples would knowingly test positive for PDCoV. Site A had 12 sampled locations including feed bins, entry benches, and barn exhaust fans. Site B had 22 sampled locations including feed bins, spilled feed under feed bins, and areas of high foot traffic like barn entries, visitor log sign in, and areas around the crossover benches before the entry shower. Site C had 13 sampled locations including feed bins, netting surrounding exhaust fans near feed bins, and fan exhaust shrouds. Feed mill sampling locations included high-risk ingredients like porcine derived ingredients, areas of high foot or vehicle traffic (receiving and load out bay and warehouse floor), feed trucks going from farm to feed mill, and bulk feed bins. Feed delivery surfaces were those within the feed delivery trucks including dashboards, foot mats, truck steps, and driver seats. Feed mill 1 had 42 samples and feed mill 2 had 44 samples.

In addition to sampling the feed mills, audits were conducted using the Kansas State University Swine Feed Mill Biosecurity Audit template (https://www. asi.k-state.edu/research-and-extension/ swine/biosecurity\%20audit.doc). The audit evaluated the biosecurity practices within the feed mill and the feed delivery system and was completed by one member of the research team by systematically proceeding through the audit document. Feed mill 1 was well kept and clean. Employees had a good understanding of biosecurity and good feed mill practices. Feed delivery trucks were required one night down time between sites and washed once deliveries were finished. However, to prepare for the upcoming holiday season, the warehouse was more crowded than normal resulting in occasional spillage and bag ripping. If spillage occurred, these ingredients are swept up and discarded in the garbage. Feed mill 2 was generally clean and well kept; the receiving pit was covered, warehouse was swept and well maintained, and the mill only manufactured swine diets. When talking with the feed delivery driver, washing trucks and sanitizing wheels and wheel wells were done as biosecurity practices when delivering to various phases of swine production systems. However, there was a porcine-based ingredient on location (choice-white grease) and this facility only had one mixer, so all diets went through the same equipment. Truck drivers were allowed to walk through the warehouse without shoe covers and feed trucks were allowed to haul diet ingredients and complete diets in the same trailer. Both the choice-white grease and no clear standard operating procedures (SOPs) for truck drivers had the potential to introduce PDCoV, PEDV, or other diseases within the feed mill and unintentionally contaminate other production sites and animals.
Environmental sampling was performed using one of two methods depending upon accessibility of sampling locations. The first method utilized a premoistened 10 - $\mathrm{cm}$ square cotton gauze surgical sponge as previously described. ${ }^{5}$ This method was used when sample areas were easily accessible and the selected area could be swabbed by hand. The second method used premoistened paint roller covers (Marathon $22.9 \mathrm{~cm} \times 0.95 \mathrm{~cm}$ nylon/ polyester paint roller cover; Purdy North America) and a paint roller extension set (152 cm fiberglass paint roller frame utility pole; Mr. LongArm, Inc) as previously described. ${ }^{3}$ The second method was used when sampling was particularly challenging, for example, inside of feed bins. Samples were placed on ice and transported back to Manhattan, Kansas. Before submitting to the lab, surgical gauze environmental swabs had $20 \mathrm{~mL}$ of phosphate buffered solution (PBS) added to the conical tube and manually agitated while paint rollers were squeezed inside the transportation plastic bag (Ziploc one-gallon size freezer bags; S.C. Johnson \& Son, Inc) and the liquid was poured into a conical tube. If $20 \mathrm{~mL}$ could not be extracted from the roller, approximately $20 \mathrm{~mL}$ of PBS was added onto the roller and wrung out a second time. Samples were stored at $-20^{\circ} \mathrm{C}$ until shipped to the ISU VDL. All samples were processed at ISU VDL for triplex qPCR for PEDV, PDCoV, and transmissible gastroenteritis virus (TGEV). Extractions from all samples were amplified using two amplification procedures. One amplification sequence used the standard ISU VDL cycle threshold (Ct) cutoff value of 36 and retained sample extractions were amplified using a Ct cutoff value of 45 .

For the first round of qPCR analysis, 17 of 133 samples (12.8\%) had detectable PEDV or PDCoV RNA with a Ct cutoff value of 36 (Table 1). Site A had 4 environmental swabs with detectable PDCoV RNA taken from the fans outside the gestation and farrowing barns and on the clean and dirty side of the entrance bench (Table 2). Site B had 6 environmental swabs with detectable PDCoV RNA taken from a feed bin outside the GDU, spilled feed outside the bin, footpath to the barn entrance, beneath shoes on the entrance floor, clean side of the entrance bench, and outside the barn entrance. Site $C$ had 5 environmental swabs with detectable PDCoV RNA taken from exhaust fan netting around 4 different feed bins and a gestation barn fan shroud. Feed mill 2 
Table 1: Number of environmental swabs positive for viral RNA collected from live animal production sites and feed mills

\begin{tabular}{|c|c|c|c|c|c|c|c|}
\hline \multirow[b]{3}{*}{ Location } & \multirow[b]{3}{*}{ Zone } & \multicolumn{6}{|c|}{ qPCR Ct limit } \\
\hline & & \multicolumn{2}{|c|}{ PDCoV } & \multicolumn{2}{|c|}{ PEDV } & \multicolumn{2}{|c|}{ TGEV } \\
\hline & & 36 & 45 & 36 & 45 & 36 & 45 \\
\hline \multirow{3}{*}{ Site A } & Feed bin - feed contact $(n=8)$ & 0 & 0 & 0 & 0 & 0 & 0 \\
\hline & Surfaces exterior facility $(n=2)$ & 2 & 2 & 0 & 0 & 0 & 0 \\
\hline & Personnel entry $(n=2)$ & 2 & 2 & 0 & 0 & 0 & 0 \\
\hline \multirow{4}{*}{ Site B } & Feed bin - feed contact $(n=13)$ & 1 & 6 & 0 & 0 & 0 & 0 \\
\hline & Feed sample $(n=1)$ & 0 & 0 & 0 & 0 & 0 & 0 \\
\hline & Feed spills exterior facility $(n=3)$ & 1 & 3 & 0 & 0 & 0 & 0 \\
\hline & Personnel entry $(n=6)$ & 4 & 6 & 0 & 0 & 0 & 0 \\
\hline \multirow{2}{*}{ Site C } & Feed bin - feed contact $(n=6)$ & 0 & 0 & 0 & 0 & 0 & 0 \\
\hline & Surfaces exterior facility $(n=7)$ & 5 & 7 & 0 & 0 & 0 & 0 \\
\hline \multirow{3}{*}{ Mill 1} & Feed contact surface $(n=26)$ & 0 & 0 & 0 & 0 & 0 & 0 \\
\hline & Non-feed contact surface $(n=10)$ & 0 & 0 & 0 & 0 & 0 & 0 \\
\hline & Transient surface $(n=6)$ & 0 & 2 & 0 & 0 & 0 & 0 \\
\hline \multirow{3}{*}{ Mill 2} & Feed contact surface $(n=29)$ & 0 & 0 & 0 & 0 & 0 & 0 \\
\hline & Non-feed contact surface $(n=8)$ & 0 & 0 & 0 & 0 & 0 & 0 \\
\hline & Transient surface $(n=7)$ & 0 & 0 & 2 & 2 & 0 & 0 \\
\hline
\end{tabular}

$\mathrm{qPCR}=$ polymerase chain reaction; $\mathrm{Ct}=$ cycle threshold; $\mathrm{PDCoV}=$ porcine deltacoronavirus; $\mathrm{PEDV}=$ porcine epidemic diarrhea virus; TGEV = transmissible gastroenteritis virus.

had 2 environmental swabs with detectable PEDV RNA taken from the feed truck pedals and floor and feed truck steering wheel and dashboard. Feed mill 1 had no samples with detectable PEDV, PDCoV, or TGEV RNA.

For the second round of qPCR analysis, 30 of 133 samples $(22.5 \%)$ had detectable PEDV or PDCoV RNA with a Ct cutoff value of 45. Site A had no additional environmental swabs with detectable PDCoV RNA. Site B had 9 additional environmental swabs with detectable PDCoV RNA taken from 4 GDU feed bins, spilled feed by another GDU bin, spilled feed under a lactation feed bin, nursery piglet feed bin, and the floor by the visitor entry and showers. Site $C$ had 2 additional environmental swabs with detectable PDCoV RNA taken from 2 more gestation bin fan shrouds. Feed mill 1 had 2 environmental swabs with detectable PDCoV RNA taken from the feed truck steps and inside the feed truck cab. Feed mill 2 had no additional environmental swabs with detectable PEDV RNA. The site B feed sample submitted on November 30, 2020 was confirmed nondetectable for PEDV, TGEV, and PDCoV on December 2, 2020 at both cutoff values.

\section{Discussion}

For this investigation, nonfeed contact surfaces were the majority of surfaces contaminated with PDCoV and PEDV. Since sites A, B, and C conducted controlled oral exposure once clinical signs appeared, PDCoV quickly dispersed through the environment and could be found on all surfaces including exhaust fans, exhaust fan netting, and fan shrouds. Research done with PEDV has found that once introduced, nucleic acids for the virus can be found throughout the environment. ${ }^{6}$ Investigations like this should consider whether locations have used controlled oral exposure as a disease management strategy because environmental sampling will be of lesser value due to the nature of controlled oral exposure. Interestingly, the only surfaces associated with the feed mill that had detectable RNA for porcine enteric viruses were from the feed delivery system. These surfaces are freely movable, or transient in nature, and able to travel from one farm to the next which is probably how these surfaces became contaminated with virus. Others have found that surfaces associated with the feed supply chain contributed to the spread of African swine fever virus (ASFV) while feed contact surfaces were negative for ASFV. ${ }^{7}$ Another study found that contaminated personal protective equipment and people can contribute to the spread of PEDV. ${ }^{8}$ These findings highlight the importance of preventing pathogen introduction into the feed mill and the feed to eliminate potential transmission. An important, but not unexpected, takeaway message from the current investigation was that contamination with PDCoV can be found outside of clinically affected farms and that this contamination can be detected in high traffic areas for personnel and trucks. This highlights the need to implement or revisit biosecurity protocols for employees and truck drivers. While these protocols may be labor or cost intensive, it is pivotal that all people and vehicles moving in and out of the supply chain understand the importance of following and maintaining good biosecurity to control the spread of disease.

Another finding of this investigation is that neither feed mill had detectable quantities of enteric coronaviruses in environmental samples. When conducting 
Table 2: Summary of qPCR Ct values for positive samples from live animal production sites and feed mills

\begin{tabular}{|c|c|c|c|c|c|c|c|}
\hline \multirow[b]{3}{*}{ Location } & \multirow[b]{3}{*}{ Sampling location } & \multicolumn{6}{|c|}{ qPCR Ct limit } \\
\hline & & \multicolumn{2}{|c|}{ PDCoV } & \multicolumn{2}{|c|}{ PEDV } & \multicolumn{2}{|c|}{ TGEV } \\
\hline & & 36 & 45 & 36 & 45 & 36 & 45 \\
\hline \multirow{4}{*}{ Site A } & Farrowing exhaust fan & 31.7 & 31.1 & ND & ND & ND & ND \\
\hline & Gestation exhaust fan & 29.3 & 28.6 & ND & ND & ND & ND \\
\hline & Dirty side of entrance bench & 29.5 & 29.1 & ND & ND & ND & ND \\
\hline & Clean side of entrance bench & 35.5 & 36.0 & ND & ND & ND & ND \\
\hline \multirow{15}{*}{ Site B } & GDU Bin 1 & ND & 38.8 & ND & ND & ND & ND \\
\hline & Spilled feed under GDU bins & 35.7 & 36.2 & ND & ND & ND & ND \\
\hline & GDU Bin 2 & 33.0 & 32.6 & ND & ND & ND & ND \\
\hline & GDU Bin 3 & ND & 38.0 & ND & ND & ND & ND \\
\hline & GDU Bin 4 & ND & 36.9 & ND & ND & ND & ND \\
\hline & GDU Bin 5 & ND & 37.8 & ND & ND & ND & ND \\
\hline & Spilled feed under gestation bins & ND & 38.7 & ND & ND & ND & ND \\
\hline & Spilled feed under lactation bins & ND & 38.9 & ND & ND & ND & ND \\
\hline & Nursery holding room feed bin & ND & 36.4 & ND & ND & ND & ND \\
\hline & Foot path exterior to facility & 33.4 & 33.0 & ND & ND & ND & ND \\
\hline & Beneath shoe on floor & 29.1 & 28.7 & ND & ND & ND & ND \\
\hline & Clean side of bench & 35.2 & 34.7 & ND & ND & ND & ND \\
\hline & Floor by visitor log & ND & 39.1 & ND & ND & ND & ND \\
\hline & Floor by showers & ND & 39.0 & ND & ND & ND & ND \\
\hline & Outside near entry door & 30.5 & 30.3 & ND & ND & ND & ND \\
\hline \multirow{7}{*}{ Site C } & Netting by gestation bin 1 & 34.7 & 34.3 & ND & ND & ND & ND \\
\hline & Netting by gestation bin 2 & 30.9 & 30.2 & ND & ND & ND & ND \\
\hline & Netting by gestation bin 3 & 32.0 & 31.5 & ND & ND & ND & ND \\
\hline & Netting by gestation bin 4 & 34.7 & 33.6 & ND & ND & ND & ND \\
\hline & Fan shroud 1 & ND & 37.5 & ND & ND & ND & ND \\
\hline & Fan shroud 2 & 29.9 & 29.3 & ND & ND & ND & ND \\
\hline & Fan shroud 3 & ND & 35.7 & ND & ND & ND & ND \\
\hline \multirow{2}{*}{ Mill 1} & Feed truck - steps & ND & 37.3 & ND & ND & ND & ND \\
\hline & Feed truck - steering wheel, pedals, floor mat & ND & 37.1 & ND & ND & ND & ND \\
\hline \multirow{2}{*}{ Mill 2} & Feed truck - floor and pedals & ND & ND & 33.4 & 33.2 & ND & ND \\
\hline & Feed truck - steering wheel and dashboard & ND & ND & 35.6 & 35.0 & ND & ND \\
\hline
\end{tabular}


disease outbreak investigations, particularly those incorporating environmental sampling, collection of appropriate samples in a timely manner is critical to allow for the greatest epidemiological value. Sample collection in the current investigation took place within 48 hours of notification of the desire to conduct sampling by the involved parties. When using environmental sampling to aid in a diagnostic investigation, the sooner the samples can be collected the lower likelihood of secondary epidemiological links causing confounding. A list of sampling locations was generated based on previous feed investigation experience to maximize the likelihood of detecting contamination if present. In this investigation, authors felt our response was timely to collect meaningful diagnostic information. When conducting investigations such as the one described in this manuscript, it is very important that personnel collecting samples are appropriately trained and collect samples in an aseptic manner.

Even though no swine enteric viruses were detected in either feed mill, there are multiple preventative strategies both feed mills could implement to mitigate the risk of feed delivery trucks potentially serving as vectors for disease that should remain out of the feed mill. Feed mitigants, like commercially available formaldehyde or medium chain fatty acids, can be expensive but reduce viral contamination in the feed. ${ }^{9.10}$ Another solution to help reduce introduction of pathogens into a mill would be to implement truck and visitor SOPs to improve biosecurity within the feed mill. These moving pieces within the feed mill will always be present, but additional training will help to reduce the likelihood of introducing a health hazard into the feed mill. ${ }^{11}$ During this investigation, authors would have liked more detailed record keeping and so recommend that all feed deliveries have detailed records. Feed delivery records were obtained from feed mill 2 to further investigate the presence of PDCoV inside the feed bins at site $\mathrm{B}$ but there were not sufficient details within the records to make a definitive link between the feed and outbreak of PDCoV. The records showed supply date and trip location but did not provide details on type of diet transported or what bin was filled. Since there were not enough details present in the delivery records, a link between the PDCoV outbreak and presence of PDCoV RNA in the feed bin can only be speculated. The records did show that feed was unloaded into the bins during a time when PDCoV was intentionally spread through a farm. It is possible these bins were in front of exhaust fans and the bins were unintentionally contaminated with PDCoV from exhaust air. Because the feed sample and feed mill surfaces from feed mill 2 had no detectable RNA for PEDV, PDCoV, or TGEV, a link could not be made between the feed mill and PDCoV farm outbreak. Had there been more information available from the feed records, a possible link between the outbreak and feed mill could have been identified.

Lastly, site B had the largest portion of environmental samples testing positive for PDCoV using a Ct value of 36 and 45. When the Ct cutoff was 36, only 6 of 22 samples were positive but 9 additional samples were positive when the Ct cutoff value was increased to 45 . The laboratory performing the analysis, matrix of the sample, and viral load of the sample must all be considered when interpreting diagnostic sample results. ${ }^{12}$ There are differences between diagnostic laboratories regarding primers and threshold limit values. Current molecular based diagnostic techniques are not validated for environmental swabs or feed/ ingredient samples and consequently care must be taken when interpreting diagnostic results. In this investigation, using a Ct limit of 45 cycles resulted in a greater number of positive samples. Given where these samples were collected, it was logical there would be virus present, albeit at a low level. Thus, increasing the Ct limit from 36 to 45 within this investigation likely increased the sensitivity of detecting environmental contamination with PDCoV. While increasing the Ct cutoff value to 45 increased the sensitivity of the test results, this practice also may increase the rate of false-positive results. The purpose of this investigation was to identify areas of contamination and make biosecurity recommendations based on results. When interpreted appropriately, having a greater diagnostic sensitivity can help identify areas of concern and the consequences of false positives are outweighed by the value of increased sensitivity in this situation. Individuals must be cautious when interpreting results near the limit of detection for diagnostic assays, but if used appropriately, increasing the Ct limit as demonstrated in the current report can add value to diagnostic investigations using environmental swabs and feed/ingredient matrices.
To further understand the possible connection between the farms with clinical disease, genetic comparison of viruses through sequencing could be a useful tool. However, this was not possible in the current investigation. Additionally, a limitation of the qPCR assay used in the current experiment is that no information is provided regarding the ability for the identified genetic material to be infectious. The assay simply detects a specific sequence of RNA and provides no information regarding potential infectivity. Additional work is necessary to further understand the infectivity characteristics of environmental swabs in diagnostic investigations, but when results are interpreted appropriately qPCR can serve as a rapid, cost-effective diagnostic tool that can provide useful information.

In conclusion, this diagnostic investigation did not find evidence within the feed supply chain indicating feed or feed delivery was associated with outbreaks of PDCoV. Due to the nature of timing, it is believed that the contamination identified at the infected sites was due to the intentional exposure through controlled oral exposure. Furthermore, it is not known what the specific mechanism of transmission was to these farms, although other routes must be considered such as personnel and other possible fomites such as incoming supplies. The goal of this investigation was to evaluate the likelihood of a link between feed manufacturing and delivery with the outbreak of clinical disease, so greater investigation into potential routes of entry were not explored. This investigation highlights the importance of biosecurity during controlled oral exposure because viral contamination can be detected outside of the farm perimeter and common events such as feed delivery may serve as a mechanism for transfer of viral contamination back to the feed mill or to other farms. The current investigation emphasizes the importance of biosecurity in the feed supply chain at both the feed manufacturing and delivery stages, with particular focus needing to be directed towards personnel movement.

\section{Implications}

Under the conditions of this report:

- People and transportation vehicles can serve as fomites for pathogens.

- No evidence of contamination within the feed mills for PDCoV was detected. 


\section{Acknowledgments}

Appreciation is expressed to Caitlin Evans, Kara Dunmire, and Savannah Stewart for assisting with sample collection during this investigation. Funding for this investigation was provided by Swine Health Information Center.

\section{Conflict of interest}

None reported.

\section{Disclaimer}

Scientific manuscripts published in the Journal of Swine Health and Production are peer reviewed. However, information on medications, feed, and management techniques may be specific to the research or commercial situation presented in the manuscript. It is the responsibility of the reader to use information responsibly and in accordance with the rules and regulations governing research or the practice of veterinary medicine in their country or region.

\section{References}

1. Niederwerder MC, Hesse RA. Swine enteric coronavirus disease: A review of 4 years with porcine epidemic diarrhea virus and porcine deltacoronavirus in the United States and Canada. Transbound Emerg Dis. 2018;65:660-675. doi:10.1111/tbed.12823

2. Dee SA, Niederwerder MC, Patterson G, Cochrane R, Jones C, Diel D, Brockhoff E, Nelson E, Spronk G, Sundberg P. The risk of viral transmission in feed: What do we know, what do we do? Transbound Emerg Dis. 2020;67:2365-2371. doi:10.1111/ tbed.13606
3. Dee S, Clement T, Schelkopf A, Nerem J, Knudsen D, Christopher-Hennings J, Nelson, E. An evaluation of contaminated complete feed as a vehicle for porcine epidemic diarrhea virus infection of naïve pigs following consumption via natural feeding behavior: Proof of concept. BMC Vet Res. 2014;10:176. doi:10.1186/s12917-014-0176-9

4. Schumacher LL, Huss AR, Cochrane RA, Stark CR, Woodworth JC, Bai J, Poulsen EG, Chen Q, Main RG, Zhang J, Gauger PC, Ramirez A, Derscheid RJ, Magstadt DM, Dritz SS, Jones CK. Characterizing the rapid spread of porcine epidemic diarrhea virus (PEDV) through an animal food manufacturing facility. PLOS ONE. 2017;12(11):e0187309. doi:10.1371/journal. prone.0187309

5. Huss AR, Schumacher LL, Cochrane RA, Poulsen E, Bai J, Woodworth JC, Dritz SS, Stark CR, Jones CK. Elimination of porcine epidemic diarrhea virus in an animal feed manufacturing facility. PLoS ONE. 2017;12(1):e0169612. doi:10.1371/ journal.pone.0169612

6. Niederwerder MC, Nietfeld JC, Bai J, Peddireddi L, Breazeale B, Anderson J, Kerrigan MA, An B, Oberst RD, Crawford $\mathrm{K}$, Lager KM, Madson DM, Rowland RRR, Anderson GA, Hesse RA. Tissue localization, shedding, virus carriage, antibody response, and aerosol transmission of porcine epidemic diarrhea virus following inoculation of 4-week-old feeder pigs. J Vet Diagn Invest. 2016;28(6):671-678. doi:10.1177/1040638716663251

7. Gebhardt JT, Dritz SS, Jones CK, Woodworth JC, Paulk CB. Lessons learned from preliminary monitoring for African swine fever virus in a region of ongoing transmission. J Am Vet Med Assoc. 2021;258(1):35-38. doi:10.2460/ javma.258.1.35
8. Kim Y, Yang M, Goyal SM, Cheeran MCJ, Torremorell M. Evaluation of biosecurity measures to prevent indirect transmission of porcine epidemic diarrhea virus. BMC Vet Res. 2017;13:89. doi:10.1186/ s12917-017-1017-4

9. Dee S, Neill C, Clement T, ChristopherHennings J, Nelson E. An evaluation of a liquid antimicrobial (Sal CURB ${ }^{\circledR}$ ) for reducing the risk of porcine epidemic diarrhea virus infection of naïve pigs during consumption of contaminated feed. BMC Vet Res. 2014;10:220. doi:10.1186/ s12917-014-0220-9

10. Lerner AB, Cochrane RA, Gebhardt JT, Dritz SS, Jones CK, De-Rouchey JM, Tokach MD, Goodband RD, Bai J, Porter E, Anderson J, Gauger PC, Magstadt DR, Zhang J, Bass B, Karnezos T, de Rodas B, Woodworth JC. Effects of medium chain fatty acids as a mitigation or prevention strategy against porcine epidemic diarrhea virus in swine feed. J Anim Sci. 2020;98(6):skaa159. doi:10.1093/jas/ skaa159

11. Cochrane RA, Dritz SS, Woodworth JC, Stark CR, Huss AR, Cano JP, Thompson RW, Fahrenholz AC, Jones CK. Feed mill biosecurity plans: A systematic approach to prevent biological pathogens in swine feed. J Swine Health Prod. 2016;24(3):154-164.

*12. Schumacher LL. Evaluation of porcine epidemic diarrhea virus in feed manufacturing. Dissertation. Kansas State University; 2016.

* Non-refereed reference. 